Revista Latinoamericana de la Papa 21 (2): 97 - 105

ISSN: $1853-4961$

http://www.papaslatinas.org/ojs/index.php/index/oai

\title{
Sistema de Inmersión Temporal en la propagación de minitubérculos semilla de papa
}

\section{H.J. Andrade-Bolaños ${ }^{1}$, F.E. Mullo-Panoluisa ${ }^{2}$, V.N. Rojas - Olmedo ${ }^{3}$}

Recibido: $21 / 04 / 2017$

Aceptado: 23/10/2017

Acceso en línea: Diciembre 2017

\section{Resumen}

Los sistemas de inmersión temporal (SIT) complementados con el autotrófico hidropónico $(\mathrm{SAH})$, se ensayaron, con el objetivo de acelerar el proceso de propagación de semilla prebásica de papa (Solanum tuberosum L.) de las variedades Superchola y Diacol-Capiro. Los resultados de los datos técnicos evaluados en las plántulas en los dos sistemas bajo las condiciones del sitio de implementación, presentaron varias ventajas en el incremento vegetativo, sobre el total de número de segmentos nodales obtenidos por biorreactor, que fueron de 322 y 264 para Superchola y Diacol-Capiro respectivamente, estos valores corresponden a la obtención de 81 tubos de ensayo $(1,8 \times 14 \mathrm{~cm})$, que ocupan una área de $2041.2 \mathrm{~cm}^{2}$ y con reducción en el ciclo de producción comparado con el sistema tradicional de cultivo en agar in vitro en quince días. Las tasas de multiplicación en los biorreactores para Superchola y Diacol-Capiro fueron 1:9 y 1:8, respectivamente. En invernadero la tasa de producción por área fue $>366$ minitubérculos por $\mathrm{m}^{2}$ en la variedad Superchola y en DiacolCapiro fue de 225 minitubérculos por $\mathrm{m}^{2}$. El rendimiento promedio de $3.75 \mathrm{~kg}$. $\mathrm{m}^{2}$ es superior a los obtenidos en plántulas in vitro en el sistema convencional y semihidropónico. $\mathrm{Al}$ comparar las dos variedades, Superchola alcanzó la mejor respuesta con rendimientos superiores en el número de tubérculos del $20 \%$ con respecto a Diacol-Capiro. El análisis financiero determinó una relación Beneficio/Costo para Superchola de 1.27 con una ganancia de 0.27 USD por cada dólar invertido. Este sistema puede proveer un método conveniente que puede ser adaptado para la propagación in vitro comercial.

Palabras claves adicionales: biorreactor, sustrato, micropropagación, minitubérculos, Solanum tuberosum..

\section{Potato mini tubers seed propagation using temporary immersion system}

\section{Summary}

A temporary immersion system was tested to accelerate the procurement of pre-basic seed category of two varieties for agroindustry, Superchola and Diacol-Capiro (Solanum tuberosum L.) in addition to the autotrophic hydroponic system. The results of the proposed system presented several advantages compared to in vitro produced seed and semi-hyroponic seedlings. The vegetative part was increased in the total number of node segments obtained by the bioreactor, 322 and 264 for Superchola and Diacol-Capiro respectively. These values corresponded to the production of 81 test tubes $(1,8 \times 14 \mathrm{~cm})$, which occupied an area of $2041,2 \mathrm{~cm}^{2}$. The production cycle was also shorter than the traditional in vitro agar culture

\footnotetext{
* Autor para correspondencia. Correo electrónico: handrade@uce.edu.ec

1 Profesor-Investigador Facultad de Ciencias Agrícolas. Universidad Central del Ecuador, Quito, Ecuador.

2 Estudiante FCA-UCE actualmente en estudios de Maestría en la Universidad del Pueblo Rusia.

3 Personal Administrativo FCA-UCE
} 
system in fifteen days. The multiplication rates for Superchola and Diacol-Capiro were 1:9 and 1:8. The production rate per area was $>366$ minitubers per $\mathrm{m}^{2}$ in Superchola and 225 minituber per $\mathrm{m}^{2}$ in Diacol-Capiro. The average yield of $3.75 \mathrm{~kg} . \mathrm{m}^{-2}$ is higher than those obtained in vitro and semi-hydroponic seedlings. Superchola achieved the best response with superior yields (tuber quantity) 20\% over Diacol-Capiro. The cost/profit ratio of 1.27 defined Superchola as the most profitable under the proposed seed production system with a return of 0.27 USD per invested dollar. This system can be adapted for commercial in vitro potato seed propagation.

Addditional Keywords: bioreactor, substrate, micropropagation, minitubers, Solanum tuberosum,

\section{Introducción}

La semilla es uno de los principales factores limitantes en la producción del cultivo de la papa, sin semilla de buena calidad, los rendimientos serán los menores, aunque se hayan optimizado los demás componentes de manejo. El proceso de producción de semilla de calidad empieza en el laboratorio y termina en el almacén (Chuquillanqui et al. 2010).

La producción de grandes cantidades de minitubérculos de alta calidad sanitaria y a bajo precio es esencial para un abastecimiento económicamente viable de semilla de papa (Andrade 1998).

La biotecnología, ha contribuido a la propagación de semilla de papa de alta calidad, mediante la implementación de técnicas especializadas como: termoterapia, cultivo de meristemas, multiplicación de plántulas in vitro $y$ producción de tubérculos prebásicos bajo condiciones ambientales controladas con estrictas normas técnicas y de calidad sanitaria (Velásquez 2013). Actualmente, la producción de semilla está basada en el sistema tradicional de cultivo in vitro en agar $y$ el subsecuente trasplante a invernadero para la producción de minitubérculos como primera generación ex vitro (Ritter et al., 2001). Las dos variedades evaluadas, son las de mayor demanda por la agroindustria de papa frita tipo bastones, debido a sus características intrínsecas de calidad como alto contenido de materia seca y bajo en azúcares reductores. Los objetivos fueron acelerar el proceso de propagación de semilla prebásica de las variedades de papa Diacol-Capiro y Superchola (Solanum tuberosum L.), utilizando el sistema de inmersión temporal (SIT), complementado con el sistema autotrófico hidropónico (SAH).

\section{Materiales y métodos}

La presente investigación se desarrolló en la provincia de Pichincha, en el Campo Docente Experimental "La Tola" (CADET) de la Facultad de Ciencias Agrícolas que pertenece a la Universidad Central del Ecuador (Tabla 1).

Tabla 1. Ubicación del sitio experimental para la producción de semilla prebásica de papa (Solanum tuberosum L.) de dos variedades para la agroindustria.

\begin{tabular}{ll}
\hline Ubicación & \\
\hline Provincia & Pichincha \\
Cantón & Quito \\
Parroquia & Tumbaco \\
Altitud & $2.465 \mathrm{msnm}$ \\
Longitud & $78^{\circ} 30^{\prime} 14^{\prime}, \mathrm{O}$ \\
Latitud & $00^{\circ} 11^{\prime} 45^{\prime}, \mathrm{S}$
\end{tabular}

Fuente: Instituto Geográfico Militar. 2012

En este estudio se integraron dos técnicas de producción de semillas: sistema de inmersión temporal (SIT), complementado con el sistema autotrófico hidropónico $(\mathrm{SAH})$. En la Tabla 2, se presentan las características climáticas del CADET donde se evaluó el ensayo. 
Tabla 2. Características climáticas del invernadero de producción.

\begin{tabular}{ll}
\hline Temperatura máxima $\left({ }^{\circ} \mathrm{C}\right)$ & 30.95 \\
Temperatura mínima $\left({ }^{\circ} \mathrm{C}\right)$ & 27.12 \\
Temperatura promedio $\left({ }^{\circ} \mathrm{C}\right)$ & 29.17 \\
Humedad relativa $(\%)$ & 69.00
\end{tabular}

Fuente: Datos tomados en el invernadero durante el ciclo del cultivo $2012-2013$.

En la Tabla 3, se presentan las variables de respuesta evaluadas en campo y laboratorio, así como en el análisis financiero.

Tabla 3. Variables de evaluación para la producción de semilla prebásica de papa de dos variedades (Solanum tuberosum L.) para la agroindustria.

\section{Variables de Evaluación}

Fase de laboratorio/aclimatación Fase de campo Análisis Financiero

$\mathrm{N}^{\circ}$ de yemas por tallo

$\mathrm{N}^{\circ}$ de tubérculos por

Relación beneficio/costo planta

$\mathrm{N}^{\circ}$ de segmentos nodales por

$\mathrm{N}^{\circ}$ de tubérculos. $\mathrm{m}^{-2} \quad$ Valor Actual Neto

biorreactor

(VAN)

Tasa de multiplicación

Rendimiento $\left(\mathrm{kg} \cdot \mathrm{m}^{-2}\right)$

Tasa Interna de Retorno

Tamaño de brote

Longitud de raíz

Porcentaje de mortalidad

En todos los experimentos se usó el diseño completamente al azar con ocho observaciones por cada genotipo. Las parcelas experimentales fueron diferentes para cada etapa de evaluación.

Para la etapa de laboratorio, se utilizó un biorreactor de 3 litros de capacidad, al que se adicionó $500 \mathrm{ml}$ de medio de cultivo ( $\sin$ agar) a base de sales minerales de Murashige y Skoog (MS), suplementado con sacarosa, pantetonato de calcio y kinetina, donde se inoculó 34 explantes, provenientes de plántulas in vitro desarrolladas en tubos de ensayo con medio semisólido, a base de sales minerales de MS suplementado con tiamina. La extracción de tejidos se realizó a los 30 días de permanencia y crecimiento en los biorreactores, bajo condiciones controladas (16 horas luz y $18{ }^{\circ} \mathrm{C}$ de temperatura), la frecuencia y tiempo de inmersión que se utilizó fueron las descritas por Jiménez et al. (1999), cada tres horas se realizó tres minutos de inmersión.

La etapa de mantenimiento y aclimatación de plantas tuvo una duración de 15 a 21 días y se realizó en la fase de aclimatización, su unidad experimental fue un contenedor plástico de $1000 \mathrm{~cm}^{3}$ con turba estéril, donde se sembró a una densidad de 100 microesquejes, 
provenientes de los tejidos ex vitro extraídos del biorreactor. Para el riego se preparó una solución hidropónica a base de sales minerales y reguladores de crecimiento.

En la etapa de invernadero la unidad experimental fue un semillero de $4.00 \mathrm{~m} \mathrm{x}$ $1.00 \mathrm{~m} \times 0.40 \mathrm{~m}$, el trasplante se realizó de forma manual con plántulas provenientes de los microesquejes, a una densidad de 35 plantas. $\mathrm{m}^{-2}$. Todo el proceso se realizó bajo estrictas normas de asepsia. En laboratorio $\mathrm{y}$ cuarto de crecimiento se tomaron muestras al azar de ocho segmentos nodales y microesquejes; en invernadero se extrapoló la producción por planta a la densidad antes indicada por $\mathrm{m}^{2}$.

El análisis costo beneficio, se realizó en base a los costos de producción. Dentro de estos costos, se tomó en cuenta la inversión para el acondicionamiento del terreno, equipos, herramientas e insumos para el manejo del cultivo, mano de obra necesaria para las labores del cultivo y los costos indirectos dentro de la investigación.

\section{Resultados y discusión}

\section{Laboratorio}

\section{Análisis del Sistema de Inmersión Temporal (SIT)}

Se obtuvieron 322 y 264 segmentos nodales/biorreactor para Superchola y Diacol-Capiro respectivamente. El promedio obtenido fue de 6 yemas por tallo en medio líquido (Tabla 4). Estos resultados coinciden con lo reportado por Toledo (1997), observándose una ligera diferencia en el caso de Superchola, probablemente por el mejor comportamiento en las condiciones proporcionadas por este sistema.

Tabla 4. Análisis de las variables de evaluación registradas en laboratorio, después de cuatro semanas de crecimiento para la producción de semilla prebásica de papa de dos variedades (Solanum tuberosum L.) para la agroindustria.

\begin{tabular}{cccccc}
\hline Variables & Superchola & $\begin{array}{c}\text { CV } \\
\%\end{array}$ & Diacol-Capiro & $\begin{array}{c}\text { CV } \\
\%\end{array}$ & $\begin{array}{c}\text { Promedio } \\
\%\end{array}$ \\
\hline $\mathrm{N}^{\circ}$ de yemas por tallo & 7.0 & 4.5 & 6.0 & 3.8 & 65 \\
$\mathrm{SN} \square$ por biorreactor & 322.0 & 4.6 & 264.0 & 4.4 & 243 \\
Tasa de multiplicación & $1: 9$ & & $1: 8$ & & \\
\hline
\end{tabular}

Estos valores corresponden a lo obtenido de 81 tubos de ensayo $(1.8 \times 14 \mathrm{~mm})$, que ocupó una superficie de laboratorio de $2041.2 \mathrm{~cm}^{2}$. Destacando como principal ventaja, a más del espacio requerido en laboratorio, el tiempo de crecimiento en el SIT que fue quince días menor respecto al sistema convencional en medio semisólido. La tasa de multiplicación obtenida por las variedades Superchola y Diacol-Capiro fueron 1:9 y 1:8 respectivamente, ligeramente superiores a las obtenidas por Montoya et al. (2008) en la tuberización de Diacol-Capiro en biorreactores y por Toledo (1997) en el sistema hidropónico autotrófico, que fueron de 1:7 y $1: 6$ respectivamente, posiblemente por el mayor contacto del medio líquido con los tejidos y por el mejor desarrollo autotrófico que ofrece este sistema. Lo anterior concuerda con $\mathrm{Ziv}$ (2005), que señala que el cultivo en bioreactores tienen algunas ventajas comparado con el cultivo basado en agar, como un mayor control del contacto del tejido de la planta con el medio de cultivo, y una óptima nutriente y suministro de reguladores de crecimiento, al igual que la aireación y circulación del medio, la filtración del medio y la multiplicación de los cultivos. 
Muñoz et al. (2006), complementan al respecto, que cuando se utilizan segmentos nodales o cultivo de suspensiones celulares, en un medio líquido dentro de un bioreactor, los factores de la velocidad de agitación, el flujo de aire y la interacción entre estos dos tienen un efecto estadísticamente significativo sobre esta variable respuesta, con un nivel de confianza del $99 \%$.

\section{Análisis del Sistema Autortrófico Hidropónico (SAH)}

En la fase de aclimatación, la variedad Diacol-Capiro presentó en promedio tamaños de brotes más grandes $(3.75 \mathrm{~cm})$, en cambio Superchola $(2.45 \mathrm{~cm})$. (Tabla 5). Estos resultados en las dos variedades son comparables a los indicados por Rigato et al. (2001), quien utilizando SAH reporta

Tabla 5. Análisis de las variables de respuesta tomados en la fase de aclimatación, después de 15 días de crecimiento para la producción de semilla prebásica de papa (Solanum tuberosum L.) de dos variedades para la agroindustria.

\begin{tabular}{|c|c|c|c|c|c|c|c|c|c|c|}
\hline Variedad & & & Superc & hola & & & & lacol-C & apiro & \\
\hline Variable & Ápice & $\begin{array}{c}\mathrm{CV} \\
\%\end{array}$ & $\begin{array}{l}\text { Entre } \\
\text { nudo }\end{array}$ & $\begin{array}{l}\mathrm{CV} \\
\%\end{array}$ & $\begin{array}{l}\text { Promedio } \\
\mathrm{cm}\end{array}$ & Ápice & $\begin{array}{l}\mathrm{CV} \\
\%\end{array}$ & $\begin{array}{l}\text { Entre } \\
\text { nudo }\end{array}$ & $\begin{array}{l}\mathrm{CV} \\
\%\end{array}$ & $\begin{array}{c}\text { Promedio } \\
\mathrm{cm}\end{array}$ \\
\hline $\begin{array}{c}\text { Tamaño de } \\
\text { brote }\end{array}$ & 2.8 & 3.7 & 2.1 & 4.94 & 2.45 & 4.3 & 3.8 & 3.2 & 4.82 & 3.75 \\
\hline $\begin{array}{l}\text { Longitud de } \\
\text { raíz }\end{array}$ & 2.8 & 4.07 & 2.6 & 3.79 & 2.7 & 1.2 & 4.26 & 1.1 & 4.64 & 1.15 \\
\hline $\begin{array}{c}\% \\
\text { mortalidad }\end{array}$ & \multicolumn{5}{|c|}{2.05} & \multicolumn{5}{|c|}{2.6} \\
\hline
\end{tabular}

a los 14 días de aclimatación un tamaño promedio de brotes de $2.16 \mathrm{~cm}$. En cambio, el INIAP (2002) para la variedad Superchola, utilizando SAH obtuvó un promedio de $3.6 \mathrm{~cm}$ de altura, superior en $1.15 \mathrm{~cm}$ al alcanzado en este estudio $(2.45$ $\mathrm{cm})$. Estos resultados heterogéneos, posiblemente se relacionan con la presencia de ácido indolbutírico (IBA) en la solución nutritiva hidropónica y a las condiciones favorables en la fase de aclimatación como temperatura y luz (Hanhineva et al. 2005) y la variedad usada.

La longitud de raíz no fue evaluada por otros autores, sin embargo, se consideró importante en esta investigación, para observar el desarrollo y adaptabilidad de tejidos provenientes del SIT a condiciones ex vitro, ya que una planta con un sistema radicular bien desarrollado tiene mayor posibilidad de sobrevivir en invernadero.
Sobresaliendo la variedad Superchola con el promedio de $2.7 \mathrm{~cm}$.

En el porcentaje de mortalidad en las dos variedades (Tabla 5), fueron de 2.05 y 2.6 $\%$, presentando porcentajes inferiores a los señalados por INIAP (2002) del 20 al $50 \%$ en la fase de aclimatación en plantas provenientes del sistema tradicional heterotrófico para la producción de semilla prebásica de papa, debido probablemente según Rigatto et al. (2002), a la mayor capacidad autotrófica obtenida por los tejidos en el sistema de inmersión temporal.

\section{Invernadero}

La variedad Superchola presentó los mejores resultados en todos los indicadores evaluados debido a su mejor adaptación a las condiciones agroclimáticas del sitio experimental. 
El número de tubérculos por planta para las variedades Superchola y Diacol Capiro fue en promedio 8.43, casi similar a lo señalado por Mencías (2011), quien reportó un promedio de 9.56 tubérculos por planta y un coeficiente de variación de $17.37 \%$. Por otra parte Navarrete (2004), obtuvo un coeficiente de variación de $15.62 \%$ para rendimiento por planta, en la producción de tubérculo-semilla prebásica de papa en un sistema semi hidropónico, con un coeficiente ligeramente inferior a los obtenidos en esta investigación, esto debido posiblemente a la baja densidad utilizada en este ensayo que favoreció el desarrollo y producción de tubérculos en ambos cultivares.

Tabla 6. Análisis de las variables de respuesta tomadas en invernadero para la producción de semilla prebásica de papa de dos variedades (Solanum tuberosum L.) para la agroindustria.

\begin{tabular}{lccccc}
\hline \multicolumn{1}{c}{ Variables } & Superchola & $\begin{array}{c}\text { CV } \\
\text { \% }\end{array}$ & Diacol Capiro & $\begin{array}{c}\text { CV } \\
\text { \% }\end{array}$ & Promedio \\
\hline $\mathrm{N}^{\circ}$ tubérculos por planta & 9.93 & 17.24 & 6.94 & 22.77 & 8.435 \\
$\mathrm{~N}^{\circ}$ tubérculos. $\mathrm{m}^{-2}$ & 366.00 & 13.30 & 225.00 & 17.20 & 295.5 \\
Rendimiento $\left(\mathrm{kg} . \mathrm{m}^{-2}\right)$ & 4.10 & 9.01 & 3.40 & 11.90 & 3.75 \\
\hline
\end{tabular}

En el número de tubérculos por $\mathrm{m}^{2}$, la variedad Superchola mostró una producción similar a lo reportado por Paredes (2002), bajo un sistema convencional de producción con un promedio de 372.34 tubérculos.m ${ }^{-2}$ y en el caso de Diacol-Capiro la planta presentó un tamaño mediano, follaje relativamente escaso, crecimiento lento y cobertura regular, lo que generó poca adaptabilidad bajo condiciones de invernadero.

La tecnología convencional basada en el uso de sustratos sólidos muestra el desempeño económico mínimo. Esta tecnología todavía es utiliza ampliamente por muchos programas de producción de semillas en América Latina, a pesar de que los rendimientos son generalmente bajos con 6-8 mini-tubérculos por planta (Chuquillaqui et al. 2007).

Tomando en cuenta el origen de la plántula, los resultados obtenidos en la presente investigacion fueron superiores a los reportados por Pinza (1997), quien obtuvo en promedio 222.68 tubérculos.m ${ }^{-2}$ para plantas provenientes de esquejes y de 305.28 para plantulas de minitubérculos.
En el caso de las plántulas obtenidas del método in vitro se obtiene un promedio de 409.92 tubérculos.m ${ }^{-2}$, los cuales en su mayoría son de sexta y séptima categoría, mismos que no son aptos para ser utilizados directamente en campo.

Respecto al rendimiento, los promedios obtenidos fueron de $3.75 \mathrm{~kg} . \mathrm{m}^{-2}$, superior a los reportados por Horna (2004), en un manejo semi-hidropónico que fue de 2.81 kg.m ${ }^{-2}$ y a los de Navarrete (2004), quien utilizando el método autotrófico hidropónico obtuvo un rendimiento promedio de $2.63 \mathrm{~kg} \cdot \mathrm{m}^{-2}$ y utilizando plántulas provenientes del método in vitro $2.06 \mathrm{~kg} \cdot \mathrm{m}^{-2}$.

El mayor rendimiento obtenido en este ensayo se debió posiblemente al mejor comportamiento de los tejidos en el SIT ya que se encuentran sometidos a un intercambio gaseoso constante y contacto permanente con el medio nutritivo líquido, lo que deriva en una buena calidad de tejidos. Otro de los factores positivos que presentó el SIT fue la mejor calidad del sistema radicular antes del trasplante, lo que permitió que las plantas sean 
fotosintéticamente más adaptadas y con un crecimiento más rápido.

\section{Porcentaje de semilla obtenida}

En la Figura 1, se observan los calibres obtenidos por la variedad Superchola, con los siguientes porcentaje por categorías expresadas en rangos de peso de tubérculo : primera (1.36\%), segunda (3.09\%), tercera $(21.29 \%)$, cuarta $(23.22 \%)$, quinta $(23.20 \%)$, sexta $(15.83 \%)$ y séptima
(12.01\%) y para la variedad DiacolCapiro: primera $(4.15 \%)$, segunda $(8.76 \%)$, tercera $(19.82 \%)$, cuarta $(18.43$ $\%)$, quinta $(17.97 \%)$, sexta $(17.05 \%)$ y séptima $(13.82 \%)$. Fue notorio observar que la variedad Diacol-Capiro obtuvo un mayor porcentaje de categorías iniciales. Este comportamiento fue corroborado por Montoya et al. (2008), que observó mayor cantidad de tubérculos por planta (49 unidades).

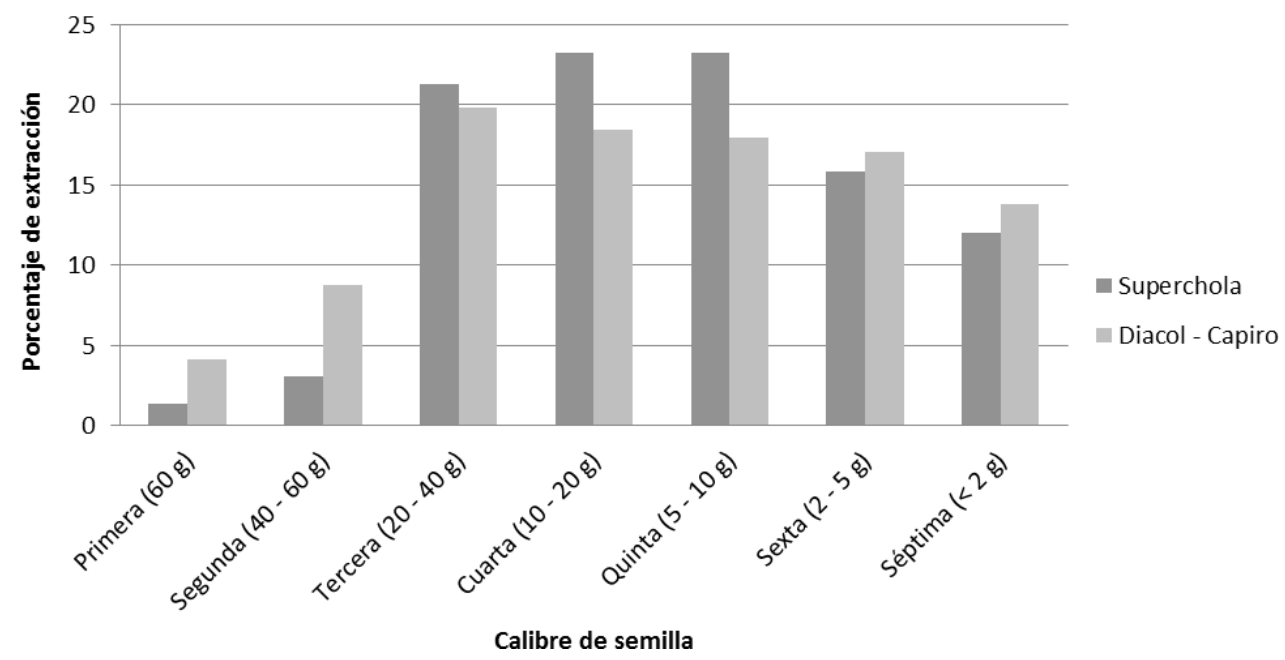

Figura 1. Porcentaje de extracción de tubérculo semilla por categoría (expresada en peso) para la producción de semilla prebásica de papa de dos variedades (Solanum tuberosum L.) para la agroindustria.

Al respecto de estos resultados Horna (2004), reportó en un sistema semihidropónico los siguientes porcentajes de semilla: primera $(1.60 \%)$, segunda $(3.15$ $\%)$, tercera $(6.49 \%)$, cuarta $(11.97 \%)$, quinta $(16.24 \%)$, sexta $(24.82 \%)$ y séptima $(35.78 \%)$ similares a los obtenidos en nuestra investigación en el caso de las dos primeras categorías, para sexta y séptima Horna reporta porcentajes superiores.

\section{Análisis financiero.}

Los parámetros más involucrados en la reducción de los costos de producción fueron: (1) la reducción drástica el uso de mano de obra; (2) la reducción en el área de la estantería; (3) reducción en el número de contenedores utilizados; (4) mejores rendimientos biológicos (Etienne et al., 2002).

La producción de grandes cantidades de minitubérculos de alta calidad y a bajo precio es esencial para un abastecimiento económicamente viable de semilla de papa (Mateus et al. 2013).

El costo total de un ciclo de producción de semilla prebásica ( 9 meses) alcanzó un 
valor de 3883.03 USD por campaña, donde los costos fijos representan el 66.2 $\%$, debido a que el personal que labora es permanente.

El costo unitario de las dos variedades en la presente investigación fue de 10.61 USD. $^{-2}$ para Superchola y de 17.26 USD. $\mathrm{m}^{-2}$ para Diacol-Capiro, por otro lado el costo por minitubérculo fue de $0.22 \mathrm{y}$ 0.36 USD respectivamente. Estos valores están basados en el número promedio de minitubérculos. $\mathrm{m}^{-2}$ obtenido en este ensayo y a la producción estimada por ciclo de producción.

\section{Análisis del beneficio/costo (B/C)}

La relación beneficio/ costo del proyecto fue de USD 1.27 para Superchola y de USD 1.06 para Diacol-Capiro, lo cual significa que, por cada dólar invertido se recupera ese dólar y se obtiene una ganancia de 27 y 6 centavos de dólar respectivamente, en el caso de Superchola es aceptable para el proceso productivo.

La TIR obtenida en el proyecto fue de $24.67 \%$, misma que es superior al costo de oportunidad del capital, lo que significa que la rentabilidad obtenida es significativa. La Tasa Interna de Retorno (TIR) es un indicador económico que iguala el Ingreso Total con el Costo Total en los valores actuales, obteniéndose el Valor Actual Neto (VAN) en donde el beneficio del proyecto es igual a cero.

Todos los parámetros financieros calculados: relación B/C, VAN y TIR fueron superior a los indicados por el sistema convencional en Perú y al semihidropónico en Ecuador para el caso de la variedad Superchola (Matheus, et al. 2012), lo que nos indica que la producción de semilla prebásica utilizando el SIT en las condiciones del CADET es rentable y competente.

\section{Conflictos de intereses}

Los autores no reportan conflicto de interés en el desarrollo de esta investigación.

\section{Referencias citadas}

Andrade, H. (1998). Variedades de papa cultivadas en el Ecuador. Superchola. INIAP, Quito, Ecuador. 3 p.

Chuquillaqui, C.; Tenorio, J.; Salazar, L. (2007). Producción de semilla de papa por hidroponía. pp. 26-34. En: Centro Internacional de la Papa (CIP). (ed.). Alternativas al uso del bromuro de metilo para la producción de semilla de papa de calidad. División de Manejo Integrado de cultivos. CIP. Lima, Perú. 53 p. Documento de trabajo 2007-2.

Chuquillanqui, C.; Mateus, J.; Barker, I.; Otazu, V. (2010). Métodos de producción de semilla Prebásica de papa. CIP, Lima, Perú. 2 p.

Etienne, H.; Berthouly M. (2002). Temporary inmersion systems in plant micropropagation. Plant Cell, Tissue and Organ Culture 69: 215-231.

Jiménez, E.; Pérez, J.; De Feria, R.; Barbón, R.; Capote, A.; Chávez, M.; Quiala, E.; Pérez, J., (1999). Improved production of potato microtubers using a temporary immersion system. Plant Cell, Tissue and Organ Culture 59:19-23

Hanhineva, K.; Kokko, H.; Ka“ Renlampi, S. (2005). Shoot regeneration from leaf explants of five strawberry (Fragaria $\mathrm{x}$ Ananassa) cultivars in temporary inmersion bioreactor system. In Vitro Cell. Dev. Biol. Plant. 41:826-831.

Horna, D. (2004). Evaluación de cuatro soluciones nutritivas para la producción de tubérculo-semilla categoría prebásica con dos cultivares de papa bajo el sistema de manejo semihidropónico. Universidad Central del Ecuador, Facultad de Ciencias Agrícolas, Quito, Ecuador. 88 p.

INIAP (2002). Aplicación del sistema Autotrófico Hidropónico (técnica Argentina) en variedades mejoradas del Ecuador para la obtención de semilla Prebásica de papa. En: Departamento de Producción de Semillas. Disponible en 
http://www. $\quad$ cipotato.org/regionquito/presentaciones/resumenes/j.benitez.d oc.pdf. Consulta: Junio, 2013.

Mateus, J.R.; De Haan, S.; Andrade, J.; Maldonado, L.; Hareau, G.; Barker I.; Chuquillanqui, C.; Otazú, V.; Frisancho, R.; Bastos, C.; Pereira, A.; Medeiros, C.; Montesdeoca, F.; Benítez, J. (2013). Technical and Economic Analysis of Aeroponics and other Systems for Potato Mini-Tuber Production in Latin America. Am. J. Potato Res. 90:357-368.

Mencias, D. (2011). Evaluación del efecto de microorganismos en la producción de semilla prebásica de papa con dos tipos de sustrato. Santa Catalina, INIAP. Universidad Central del Ecuador, Facultad de Ciencias Agrícolas, Quito, Ecuador. 138 p.

Montoya, N.; Castro, D.; Diaz, J. (2008). Tuberización in vitro de papa (Solanum tuberosum L.), variedad Diacol-Capiro, en biorreactores de inmersión temporal y evaluación de su comportamiento en campo. En: Ciencia. Maracaibo, VE. Disponible en http://www2.scielo.org.ve/scielo. php?script $=$ sci_arttext\&pid $=S 1315207620$ 0 800300003\&lng=es\&nrm=i. 16(3): 288295. Consulta: Diciembre, 2013.

Muñoz, W.; Vanegas O.; Guzmán A.; Capataz, J.; Hoyos, R.; Orozco, F. (2006). Estimación de variables de operación de un biorreactor con células de Azadirachta indica, A. Juss. Revista Agronomía 59 (2): 3467-3478.

Navarrete, J. (2004). Evaluación de dos métodos de micropropagación para la producción de semilla categoría prebásica de dos variedades de papa bajo condiciones de invernadero. Santa Catalina, INIAP. Universidad Central del Ecuador, Facultad de Ciencias Agrícolas. Quito, Ecuador. 77 p.
Paredes, M. (2002). Estudio de producción de tubérculo-semilla categoría prebásica de dos variedades de papa bajo diferentes sistemas de manejo. Santa Catalina, INIAP. Universidad Central del Ecuador, Facultad de Ciencias Agrícolas. Quito, Ecuador. 65 p.

Pinza, M. (1997). Producción de semilla Prebásica de Papa (Solanum tuberosum) en invernadero con tres orígenes y aporques, Santa Catalina, INIAP. Universidad Central del Ecuador, Facultad de Ciencias Agrícolas. Quito, Ecuador. 75 p.

Rigato, S.; González, A.; Huarte, M. (2001). Producción de plántulas por el sistema autotrófico-hidropónico. Revista Latinoamericana de la Papa 12 (1): 110 120.

Ritter, E.; Angulo, B.; Riga, P.; Herrán, J.; Relloso, J.; San José, M. (2001). Comparison of hydroponic and aeroponic cultivation systems for the production of potato mini-tubers. Potato Research. 44: 127-135.

Ritter, E., Angulo, B., Riga, P., Herrán, C., Relloso, J. 2001. Comparison of Hydroponic and Aeroponics Cultivation Systems for the Production of Potato Minitubers. Netherlands. Am. J. Potato Res. 44(2): 127-135.

Toledo, J. (1997). Producción de semilla de papa y manejo empresarial. Manejo de plántula in-vitro laboratorio e invernadero. CIP. Lima, Perú.

Velásquez, J. (2013). Semilla de papa en el país: el rol del INIAP. En: Curso de Aeroponía para la producción de minitubérculos de papa. Centro Internacional de la Papa, Quito, Ecuador.

Ziv M. (2005). Simple bioreactors for mass propagation of plants. Plant Cell, Tissue and Organ Culture. 81(3): 277-285. 